\title{
Profile of Radiation Therapy after Radical Prostatectomy: Experience in a Tertiary Hospital in Jakarta, Indonesia
}

\author{
Rama Firmanto, Agus Rizal AH Hamid, Chaidir A Mochtar, Rainy Umbas
}

Urology Department, Cipto Mangunkusumo Hospital, Jakarta

\section{ARTICLE INFO}

Received : 21 August 2019

Reviewed : 30 October 2019

Accepted : 13 January 2020

\section{Keywords:}

radical prostatectomy, radiotherapy, prostate cancer

\author{
ABSTRACT
}

Background: Despite the high recurrence rate, radical prostatectomy (RP) remains as a preferable surgical treatment of localized prostate cancer. Adjuvant radiotherapy (ART) and salvage radiotherapy (SRT) are available approaches in preventing biochemical progression after RP. We aim to investigate the use of radiotherapy, both ART and SRT, in those who underwent RP.

Methods: We used a retrospective cohort study design, with samples recruited from prostate cancer patients who underwent RP between January 2008 and December 2016. Patients who had undergone RP at Cipto Mangunkusumo Hospital, Jakarta, Indonesia were included in the present study. More in detail, three and five subjects were treated with ART and SRT, respectively. We only included those who had a minimum of one year of follow-up. Variables including age, preoperative prostate-specific antigen (PSA), clinical staging, pathological staging, Gleason score, and death were recorded. We analyzed the overall survival time using the Kaplan-Meier method.

\begin{abstract}
Results: From 34 patients included in the study, 26 underwent RP alone, while 5 patients underwent adjuvant radiotherapy and 3 patients underwent salvage radiotherapy after RP. The mean ages in the three groups were $61.46 \pm 5.76,58.2 \pm 4.86$ and $62.67 \pm 7.5$, respectively. The preoperative PSA value was above $10 \mathrm{mg} / \mathrm{dL}$ in $61.5 \%$ in patients without RT, $100 \%$ in patients with ART after RP, and none in SRT. 17 (51.5\%) out of 33 subjects were $\geq T 2$ clinical stage and $24 / 30$ (80\%) subjects were $\geq p$ T2. Timing for ART and SRT ranged from 1.07 to 6.3 and 5.27 to 21.43 months after $\mathrm{RP}$, respectively. The 10 -year survival rates were $84.6 \%$ in patients with RP alone, $80 \%$ in patients with $A R T+R P$, and $66.7 \%$ in patients with SRT+RP. The average survivals of those who had RP alone as well as ART and SRT were $44.56 \pm 32.64,46.79 \pm 24.02$, and $71.71 \pm 38.74$ months.
\end{abstract}

Conclusions: The average survival of those who received SRT is better than those who underwent ART and RP alone. Prospective studies with larger samples are needed to evaluate the efficacy of radiation therapy after radical prostatectomy.

\author{
*Corresponding author: \\ Rainy Umbas \\ Urology Department, Cipto \\ Mangunkusumo Hospital, Jakarta \\ rainy.umbas@gmail.com
}

of these patients are at risk of dying from such disease within the 15 years of biochemical progression (BCP) [7]. To date, there have been two types of radiotherapy available for treatment and prevention of such progression after RP, which are: immediate postoperative adjuvant radiotherapy (ART) and salvage radiotherapy (SRT) [3]. ART refers to the postsurgical radiotherapy given to patients who are at the high risk for recurrence but lack measurable disease, and SRT refers to radiotherapy given to patients with clinical evidence of residual or recurrent disease after surgery.

Adjuvant radiotherapy in high-risk patients was shown to increase local control rates and disease-free survival. The positive effect of ART for survival in patients diagnosed with PC is highly influenced by tumor characteristics. The fundamental premise underlying ART is that local recurrence comes first before systemic, metastatic spread occurs in the majority of those in whom RP failed [8]. 
Thus, it might be better to administer ART after RP. According to the National Comprehensive Cancer Network (NCCN), the indications of ART include those with pT3, positive SMs, Gleason scores of 8 to 10, or SVI. Usually, ART is administered within a year after surgery and once there is an improvement of the side effects of RP [9]. Recurrence, often defined as PSA values of at least $\geq 0.2$ after RP [10], is also an indication for ART.

Salvage radiotherapy is defined as radiotherapy to the prostatic bed and surrounding tissues in patients with biochemical recurrence (BCR) following RP without showing signs of distant metastases [1]. Theoretically, SRT reduces the expenses and adverse effects of ART to individuals with adverse pathologies but who have a low risk of recurrence after surgery [11-13]. To this date, there are no studies regarding the use of radiotherapy in those who underwent RP in our hospital. The present study aims to investigate the average survival of the patients who underwent ART and SRT compared to those who underwent RP but didn't get the radiotherapy.

\section{METHODS}

\section{Participant}

This was a retrospective cohort study on prostate cancer patients who underwent RP with or without additional radiation therapy during the period of January 2008 to December 2016 at Cipto Mangunkusumo
Hospital, Jakarta, Indonesia with the ethic committee approval number 1140/UN2.F1/ETIK/2018.

The sample size was initially measured using the mean survival between two groups and there are two different type groups, namely, ART and SRT groups, which were being compared with the patients without the radiation group as the control group. Since patients recruited within the study period were only 34 samples, the statistical analysis was not done due to inadequate data. Thus, a descriptive report was presented. Patients who had sufficient data and a minimum of one-year follow-up were included in the present study. Variables including age, preoperative PSA, clinical stage, pathological stage, Gleason score, and death were recorded.

\section{Statistical Analysis}

The average survival and overall survival (OS) from ART and SRT groups were calculated from the date of $\mathrm{RP}$ to the date of death or the last follow-up and were compared with the control. Since the number of recruited samples were inadequate for the statistical analysis, a descriptive report was done. The survival rate was estimated by using the Kaplan-Meier analysis.

Average survival is defined as mean survival time since the commencement of therapy (RP) until the death of each sample presented as months. Overall survival is defined as the percentage of samples who are still found to be alive after the period of follow-up.

\section{RESULTS}

Table 1. Characteristics of the subjects

\begin{tabular}{|c|c|c|c|}
\hline Characteristics & $\begin{array}{l}\text { Without radiotherapy } \\
\qquad(\mathrm{N}=26)\end{array}$ & $\begin{array}{l}\text { With adjuvant radiotherapy } \\
\qquad(\mathrm{N}=5)\end{array}$ & $\begin{array}{l}\text { With salvage radiotherapy } \\
\qquad(\mathrm{N}=3)\end{array}$ \\
\hline \multicolumn{4}{|l|}{ Age } \\
\hline Mean \pm SD & $61.46 \pm 5.76$ & $58.2 \pm 4.86$ & $62.67 \pm 7.5$ \\
\hline Median (range) & $62(44-69)$ & $55(54-64)$ & $63(55-70)$ \\
\hline \multicolumn{4}{|l|}{ Preoperative PSA } \\
\hline$<10$ & $10(38.5 \%)$ & $0(0 \%)$ & $2(66.7 \%)^{*}$ \\
\hline$\geq 10$ & $16(61.5 \%)$ & $5(100 \%)$ & $0(0 \%)$ \\
\hline Mean \pm SD & $28.19 \pm 59.3$ & $64.48 \pm 66.58$ & $6.62 \pm 3.87$ \\
\hline Median (range) & $14(0.48-308.65)$ & 32.56 (12.05-170) & $6.62(3.88-9.36)$ \\
\hline \multicolumn{4}{|l|}{ Clinical stage } \\
\hline $\mathrm{T} 1$ & $13(49.1 \%)^{*}$ & $3(60 \%)$ & $0(0 \%)$ \\
\hline$\geq \mathrm{T} 2$ & $12(46.2 \%)$ & $2(40 \%)$ & $3(100 \%)$ \\
\hline \multicolumn{4}{|l|}{ Pathological stage } \\
\hline $\mathrm{T} 1$ & $6(23.1 \%)^{* *}$ & $0(0 \%)$ & $0(0 \%)^{*}$ \\
\hline$\geq \mathrm{T} 2$ & $17(65.4 \%)$ & $5(100 \%)$ & $2(66.7 \%)$ \\
\hline \multicolumn{4}{|l|}{ Gleason score } \\
\hline$\leq 7$ & $17(65.2 \%)^{*}$ & $3(60 \%)$ & $2(66.7 \%)$ \\
\hline$\leq 8$ & $8(30.7 \%)$ & $2(40 \%)$ & $1(33.3 \%)$ \\
\hline Average survival (months) & $44.56 \pm 32.64$ & $46.79 \pm 24.02$ & $71.71 \pm 38.74$ \\
\hline
\end{tabular}

*One subject was missing

**Three subjects were missing 
A total of 34 subjects who underwent RP were recruited for this study. Twenty-six subjects did not receive additional radiotherapy, while five and three subjects had ART and SRT, respectively (Table 1). SRT was initiated in patients with PSA levels of $0.15,0.06$, and $3.9 \mathrm{ng} / \mathrm{mL}$, and ART was initiated at PSA levels of $4.28,0.16,0.206$, and $0.007 \mathrm{ng} / \mathrm{mL}$ (one subject was missing).

The average survival of the group without radiotherapy, ART group, and SRT group were $81 \%, 48 \%$, and $65 \%$ respectively. The average survival of SRT is the highest with a mean survival of $71.71 \pm 38.74$ months, followed by the ART group with a mean survival of $46.79 \pm 24.02$. The control group (without radiotherapy) had the lowest average survival with a mean survival of $44.56 \pm 32.64$. The Kaplan-Meier analysis of the survival function of the subjects is presented in Figure 1. A total of six subjects died during the follow-up period.

\section{Survival Functions}

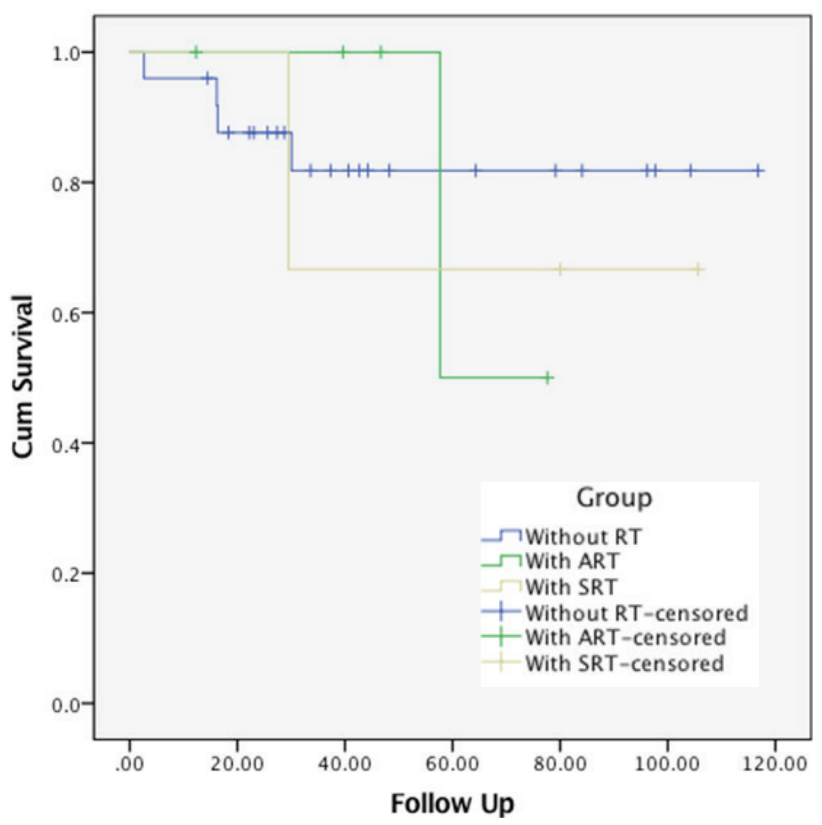

Figure 1. Kaplan-Meier analysis of the survival function of the subjects

\section{DISCUSSION}

Despite being a standard treatment for post-op RP $\mathrm{BCR}$, there is currently no consensus with regard to the optimal timing of SRT [14]. Moreover, controversy remains concerning when ART should be given after surgery [15-18]. In the present study, the timing for ART and SRT ranged from 1.07 to 6.3 and 5.27 to 21.43 months after RP, respectively.

In this study, the three subjects that received SRT had pre-RT PSA levels of $0.06,0.15$, and $3.9 \mathrm{ng} / \mathrm{mL}$. King suggested that SRT should be initiated at the lowest possible PSA [19]. In a study comparing the outcomes of different timings of the administration of SRT after postoperative BCR with the median follow-up of 70 months, Taguchi et al. [14] found that four (20\%), nine (23), and seven (44\%) patients had biochemical failure in ultra-early SRT (given before the patients meet criteria of two consecutive PSA values $\geq 0.2 \mathrm{ng} / \mathrm{mL}$ ). Early SRT administered at pre-radiation PSA $\leq 0.5 \mathrm{ng} / \mathrm{mL}$ and delayed SRT given after PSA reached $0.5 \mathrm{ng} / \mathrm{mL}$ groups. There was no survival benefit of ultra-early SRT compared to early SRT. However, delayed SRT was associated with poorer prognosis. Stephenson et al. [20] reported that the 6-year BCR-free survival rates were between $50 \%$ and $18 \%$ among patients with PSA levels of $\leq 0.5$ and $>1.5 \mathrm{ng} / \mathrm{ml}$ at the initiation of RT, respectively. Another study that included individuals receiving only early SRT, defined as post-operative RT at PSA values $\leq 0.5 \mathrm{ng} / \mathrm{ml}$, showed a 5-year BCR-free survival rate of approximately 75\% [21]. However, whether early SRT has similar efficacy as ART after RP should be further investigated in prospective RCTs. A multicenter retrospective study reported that the initial observation followed by early SRT showed a comparable BCR-free survival to ART in men with PT3NO disease using a matched-controlled approach [13]. The investigators, however, failed to show any difference in the 5-year recurrence-free survival rates between the two groups in an approximately 1000 patient population with aggressive pathologic characteristics. (78.4 vs $81.8 \%$ for adjuvant vs. observation eventually followed by SRT, respectively) [13].

Despite the fact that administering ART in all men had no justification, the existing evidence demonstrates those with men with positive SMs and PT3 PC have more than $50 \%$ risk of biochemical within 10 years after RP [22-24]. Thus, those with such diseases are considered suitable candidates for undergoing ART. A Cochrane review study of 3 RCTs with 1.815 high-risk patients at the time of surgery (e.g., SVI) showed that ART improved biochemical progress-free survival (PFS) in comparison to RP alone at 5 and 10 years (risk difference at 5 years: $-0.16 ; 95 \% \mathrm{Cl}:-0.21$ to 0.11 and at 10 years: $-0.29 ; 95 \% \mathrm{Cl}: 0.39$ to 0.19 ) (49) [25]. According to the NCCN, the indications of ART include PT2 disease, positive SMs, Gleason scores of 8 to 10 , or SVI. ART is usually given within a year after RP and once there is an improvement of any side effects of RP $[9,26,27]$.

Other findings also suggest that ART may reduce the BCR hazard ratio [HR] significantly in the presence of adverse pathology after RP, despite lower RT doses than usual [28-31]. However, these studies contained major contamination biases; such as $30-35 \%$ of the included subjects had detectable PSA and thus received SRT rather than ART. These make the efficacy data questionable. The use of postoperative RT might increase the risks of toxicities in both short and long terms, which may impair patients' quality of life. In the SWOG 
8794 trial, those who received ART developed a rectal complication, urethral stricture, and urinary incontinence compared to controls [32]. The EORTC 22863 trial also showed that the incidence of genitourinary toxicity and other late adverse events, during 10 years of follow-up, were higher among patients treated with immediate postoperative RT [15]. A systematic review involving three RCTs revealed that ART increased the risk of acute and late gastrointestinal problems, urinary stricture, and worse continence recovery rates [33]. Whereas, retrospective studies focusing on patients treated with SRT showed that this radiotherapy might lead to grade 2 or higher genitourinary toxicities in up to $20 \%$ of the patients [34,35]. In addition, previous studies that compared the safety profile of postoperative ART and SRT failed to show significant differences between both approaches [35,36].

The advantages of administering ART immediately are more evident from three RCTs. These trials demonstrated that those who underwent ART achieved $20 \%$ higher biochemical control at 5 years compared to those undergoing SRT $[15,32,37,38]$. Nevertheless, it should be considered that in two out of three RCTs, more than a quarter of the included subjects had PSA levels higher than $0.2 \mathrm{ng} / \mathrm{mL}$ at the time RT began. This corresponds to a "salvage-like" situation [15,32]. Our study was limited by the small number of post-RP patients receiving ART or SRT.

\section{CONCLUSIONS}

The highest average survival group was SRT with a mean survival of $71.71 \pm 38.74$ months, followed by ART group with a mean survival of $46.79 \pm 24.02$. The control group (without radiotherapy) had the lowest average survival with a mean survival of $44.56 \pm 32.64$. Patients who underwent SRT have better average survival than those undergoing RP alone or ART. Further studies with prospective study design and larger samples are needed to evaluate the efficacy of radiation therapy after radical prostatectomy.

\section{DECLARATIONS}

\section{Competing of Interest}

The author(s) declare no competing interest in this study.

\section{Acknowledgement}

The Author(s) wish to thank our colleagues and our teacher from Urology Department Cipto Mangunkusumo Hospital who provided insight and expertise that greatly assisted the research.

\section{REFERENCES}

1. Thompson IM, Valicenti RK, Albertsen P, Davis BJ, Goldenberg SL, Hahn C, et al. Adjuvant and salvage radiotherapy after prostatectomy: AUA/ASTRO guideline. J Urol. 2013;190(2):441-9.

2. Umbas R, Safriadi F, Mochtar CA, Djatisoesanto W, Hamid ARAH. Urologic cancer in Indonesia. Jpn J Clin Oncol. 2015;45(8):708-12.

3. Cremers RGHM, van Lin ENJT, Gerrits WLJ, van TolGeerdink JJ, Kiemeney LALM, Vergunst $\mathrm{H}$, et al. Efficacy and tolerance of salvage radiotherapy after radical prostatectomy, with emphasis on high-risk patients suited for adjuvant radiotherapy. Radiother Oncol. 2010;97(3):467-73.

4. Pound CR, Partin AW, Eisenberger MA, Chan DW, Pearson JD, Walsh PC. Natural history of progression after PSA elevation following radical prostatectomy. J Am Med Assoc. 1999;281(17):1591-7.

5. Carver BS, Bianco FJ, Scardino PT, Eastham JA. LongTerm Outcome Following Radical Prostatectomy in Men With Clinical Stage T3 Prostate Cancer. J Urol. 2006;176(2):564-8.

6. Hayes SB, Pollack A. Parameters for treatment decisions for salvage radiation therapy. J Clin Oncol. 2005;23(32):8204-11.

7. Freedland SJ, Humphreys EB, Mangold L a, Eisenberger M, Dorey FJ, Walsh PC, et al. Risk of prostate cancerspecific mortality following biochemical recurrence after radical prostatectomy. JAMA. 2005;294(4):433-9.

8. Detti B, Scoccianti S, Cassani S, Cipressi S, Villari D, Lapini $A$, et al. Adjuvant and salvage radiotherapy after prostatectomy: Outcome analysis of 307 patients with prostate cancer. J Cancer Res Clin Oncol. 2013;139(1):145-57.

9. NCCN. NCCN Clinical Practice Guidelines in Oncology (NCCN Guidelines ${ }^{\circledR}$ ) Prostate Cancer. Version 1.2017. 2017.

10. Mir MC, Li J, Klink JC, Kattan MW, Klein EA, Stephenson AJ. Optimal definition of biochemical recurrence after radical prostatectomy depends on pathologic risk factors: Identifying candidates for early salvage therapy. Eur Urol. 2014;66(2):204-10.

11. Stephenson AJ, Bolla M, Briganti A, Cozzarini C, Moul JW, Roach $M$, et al. Postoperative radiation therapy for pathologically advanced prostate cancer after radical prostatectomy. Eur Urol. 2012;61(3):443-51.

12. Pfister D, Bolla M, Briganti A, Carroll P, Cozzarini C, Joniau $S$, et al. Early salvage radiotherapy following radical prostatectomy. Eur Urol. 2014;65(6):1034-43.

13. Briganti A, Wiegel $T$, Joniau S, Cozzarini $C$, Bianchi $M$, Sun $M$, et al. Early salvage radiation therapy does not compromise cancer control in patients with PT3NO prostate cancer after radical prostatectomy: Results of a match-controlled multi-institutional analysis. Eur Urol. 2012;62(3):472-87. 
14. Taguchi S, Shiraishi K, Fukuhara H, Nakagawa K, Morikawa $T$, Naito $A$, et al. Optimal timing of salvage radiotherapy for biochemical recurrence after radical prostatectomy: is ultra-early salvage radiotherapy beneficial? Radiat Oncol. 2016;11(1):102.

15. Bolla M, Van Poppel H, Collette L, Van Cangh P, Vekemans K, Da Pozzo L, et al. Postoperative radiotherapy after radical prostatectomy: $\mathrm{A}$ randomised controlled trial (EORTC trial 22911). Lancet. 2005;380(9858):2018-27.

16. Schild SE. Radiation therapy after prostatectomy: now or later? Semin Radiat Oncol. 1998;8(2):132-9.

17. Catton C, Gospodarowicz M, Warde P, Panzarella T, Catton $P$, McLean $M$, et al. Adjuvant and salvage radiation therapy after radical prostatectomy for adenocarcinoma of the prostate. Radiother Oncol. 2001;59(1):51-60.

18. Schild SE. Radiation therapy (RT) after prostatectomy: The case for salvage therapy as opposed to adjuvant therapy. Int J Cancer. 2001;96(2):94-8.

19. King CR. The timing of salvage radiotherapy after radical prostatectomy: A systematic review. Int J Radiat Oncol Biol Phys. 2012;84(1):104-11.

20. Stephenson AJ, Scardino PT, Kattan MW, Pisansky TM, Slawin KM, Klein EA, et al. Predicting the outcome of salvage radiation therapy for recurrent prostate cancer after radical prostatectomy. J Clin Oncol. 2007;25(15):2035-41.

21. Briganti A, Karnes RJ, Joniau S, Boorjian SA, Cozzarini C, Gandaglia G, et al. Prediction of outcome following early salvage radiotherapy among patients with biochemical recurrence after radical prostatectomy. Eur Urol. 2014;66(3):479-86.

22. Roach M, Hanks G, Thames H, Schellhammer $P$, Shipley WU, Sokol GH, et al. Defining biochemical failure following radiotherapy with or without hormonal therapy in men with clinically localized prostate cancer: Recommendations of the RTOGASTRO Phoenix Consensus Conference. Int J Radiat Oncol Biol Phys. 2006;65(4):965-74.

23. Chade DC, Shariat SF, Cronin AM, Savage CJ, Karnes RJ, Blute ML, et al. Salvage radical prostatectomy for radiation-recurrent prostate cancer: A multi-institutional collaboration. Eur Urol. 2011;60(2):205-10.

24. Rocco B, Cozzi G, Spinelli MG, Grasso A, Varisco D, Coelho RF, et al. Current status of salvage robotassisted laparoscopic prostatectomy for radiorecurrent prostate cancer. Curr Urol Rep. 2012;13(3):195-201.

25. Gotto GT, Yunis LH, Vora K, Eastham JA, Scardino PT, Rabbani F. Impact of Prior Prostate Radiation on Complications After Radical Prostatectomy. J Urol. 2010;184(1):136-42.

26. Pinto F, Prayer-Galetti T, Gardiman M, Sacco E, Ciaccia M, Fracalanza S, et al. Clinical and pathological characteristics of patients presenting with biochemical progression after radical retropubic prostatectomy for pathologically organ-confined prostate cancer. Urol Int. 2006;76(3):202-8.

27. Salomon L, Anastasiadis AG, Antiphon P, Levrel O, Saint F, De La Taille A, et al. Prognostic consequences of the location of positive surgical margins in organconfined prostate cancer. Urol Int. 2003;70(4):291-6.

28. Ramey SJ, Marshall DT. Re-irradiation for salvage of prostate cancer failures after primary radiotherapy. World J Urol. 2013;31(6):1339-45.

29. Mouraviev V, Spiess PE, Jones JS. Salvage cryoablation for locally recurrent prostate cancer following primary radiotherapy. Eur Urol. 2012;61(6):1204-11.

30. Lawrentschuk N, Finelli A, Van der Kwast TH, Ryan P, Bolton DM, Fleshner NE, et al. Salvage radical prostatectomy following primary high intensity focused ultrasound for treatment of prostate cancer. J Urol. 2011;185(3):862-8.

31. Riviere J, Bernhard JC, Robert G, Wallerand H, Deti E, Maurice-Tison $S$, et al. Salvage radiotherapy after highintensity focussed ultrasound for recurrent localised prostate cancer. Eur Urol. 2010;58(4):567-73.

32. Thompson IM, Tangen CM, Paradelo J, Lucia MS, Miller G, Troyer D, et al. Adjuvant radiotherapy for pathologically advanced prostate cancer: a randomized clinical trial. JAMA J Am Med Assoc. 2006;296(19):2329-35.

33. Daly $T$, Hickey BE, Lehman M, Francis DP, See AM. Adjuvant radiotherapy following radical prostatectomy for prostate cancer. Cochrane Database Syst Rev. 2011;12:CD007234.

34. Goenka A, Magsanoc JM, Pei X, Schechter M, Kollmeier $\mathrm{M}$, Cox B, et al. Improved toxicity profile following high-dose postprostatectomy salvage radiation therapy with intensity-modulated radiation therapy. Eur Urol. 2011;60(6):1142-8.

35. Cozzarini C, Fiorino C, Da Pozzo LF, Alongi F, Berardi G, Bolognesi $A$, et al. Clinical factors predicting late severe urinary toxicity after postoperative radiotherapy for prostate carcinoma: A single-institute analysis of 742 patients. Int J Radiat Oncol Biol Phys. 2012;82(1):191-9.

36. Sowerby RJ, Gani J, Yim H, Radomski SB, Catton C. Long-term complications in men who have early or late radiotherapy after radical prostatectomy. J Can Urol Assoc. 2014;8(7-8):253-8.

37. Wiegel T, Bottke D, Steiner U, Siegmann A, Golz R, Störkel $S$, et al. Phase III postoperative adjuvant radiotherapy after radical prostatectomy compared with radical prostatectomy alone in PT3 prostate cancer with postoperative undetectable prostatespecific antigen: ARO 96-02/AUO AP 09/95. J Clin Oncol. 2009;27(18):2924-30.

38. Swanson GP, Hussey MA, Tangen CM, Chin J, Messing $E$, Canby-Hagino $E$, et al. Predominant treatment failure in postprostatectomy patients is local: Analysis of patterns of treatment failure in SWOG 8794. J Clin Oncol. 2007;25(1):2225-9. 